\section{"No volveremos a ser los mismos, asistimos a un cambio de mentalidad en la relación entre ciencia, tecnología y sociedad"}

Resumen: Entrevistamos a Roberto Salvarezza, Ministro de Ciencia, Tecnología e Innovación de la República Argentina. En su trayectoria ha logrado conjugar una labor científica destacada con la gestión pública y la actividad política. Investigador Superior del CONICET y ex Presidente del organismo, fue además Diputado de la Nación.

Palabras clave: MINCyT - Argentina - Política científica y tecnológica - CyT en Argentina - Desarrollo nacional

"We will not be the same again, we are witnessing a change in mentality in the relationship between science, technology and society"

Abstract: We interview Roberto Salvarezza, Minister of Science, Technology and Innovation of the Argentine Republic. In his career, he has managed to combine outstanding scientific work with public management and political activity. Senior Researcher of CONICET and former President of the organization, he was also a Deputy of the Nation.

Keywords: MINCyT - Argentina - Science and technology policy - Science and Technology in Argentina - National development

"Não seremos mais os mesmos; estamos testemunhando uma mudança de mentalidade na relação entre ciência, tecnologia e sociedade".

Resumo: Entrevistamos Roberto Salvarezza, Ministro da Ciência, Tecnologia e Inovação da República Argentina. Em sua carreira, ele conseguiu combinar trabalho científico destacado na gestão pública e na atividade política. Pesquisador Sênior do CONICET e ex-Presidente da entidade, também foi deputado federal.

Palavras-chave: MINCyT - Argentina - Política de ciência e tecnologia - Ciência e tecnologia na Argentina - Desenvolvimento nacional

\section{Ciencia Tecnología y Política \\ Año 4 NN$^{\circ} 6$ Mayo 2021}

Roberto Salvarezza

Entrevista a cargo de

Gabriel Bilmes y

Santiago Liaudat.

Año 4 N 6 Mayo 2021 e051

Fecha de recibido: 10/04/2021

Fecha de aprobado: 05/05/2021

https://doi.org/10.24215/26183188e051

https://revistas.unlp.edu.ar/CTyP

ISSN 2618-3188

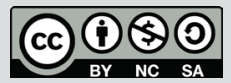

Esta obra está bajo licencia Creative Commons Atribución-NoComercial-Compartirlgual 4.0 Internacional

http://creativecommons.org/licenses/bync-sa/4.O/deed.es_AR 
Roberto Salvarezza

\section{"No volveremos a ser los} mismos, asistimos a un cambio de mentalidad en la relación entre ciencia,
tecnología y sociedad" Entrevista a cargo de Gabriel Bilmes y Santiago Liaudat.

Entrevistamos a Roberto Salvarezza, Ministro de Ciencia, Tecnología e Innovación de la República Argentina. En su trayectoria ha logrado conjugar una labor científica destacada con la gestión pública y la actividad política. Investigador Superior del CONICET y ex Presidente del organismo, fue además Diputado de la Nación. 


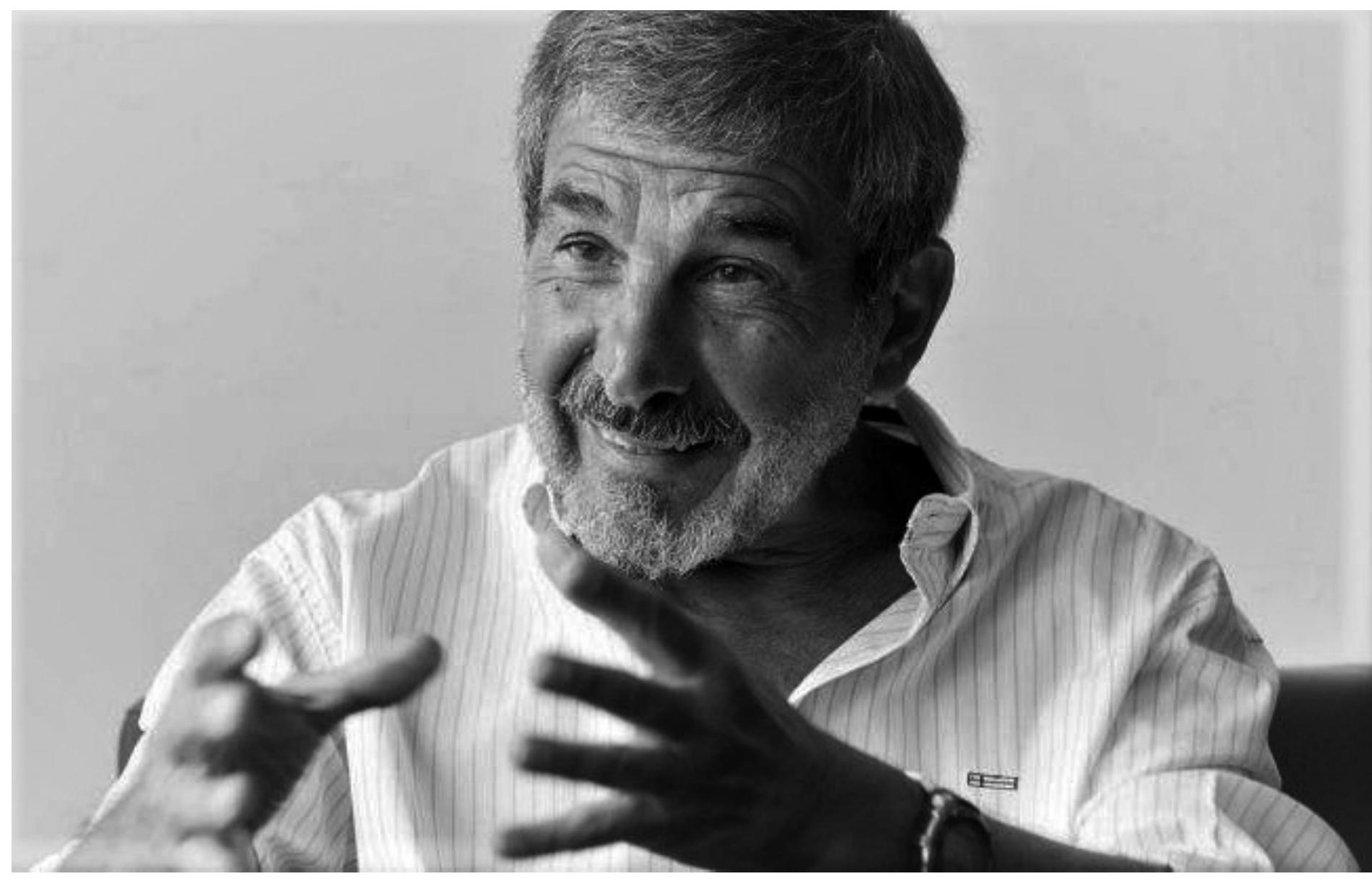

CTyP: Con un año y medio de gestión al frente del Ministerio de Ciencia, Tecnología e Innovación (MINCyT), ¿en qué situación encontraron al sector después del gobierno de Mauricio Macri? ¿Qué tipo de obstáculos enfrentaron?

RS: Encontramos, ante todo, un Ministerio que era una secretaría y que carecía de políticas. No había una política científica. Estaba totalmente desarticulado. Parte se debió al maltrato que recibió el sector de ciencia y tecnología durante el gobierno de Mauricio Macri. Eso se reflejó en la degradación del Ministerio a una Secretaria de Ciencia, Tecnología e Innovación Productiva en la que no solo no había planes, sino que tenía enormes deudas. Por mencionar algunas: la Biblioteca Electrónica de Ciencia y Tecnología se dejó de pagar, el barco "Puerto Deseado" estaba a punto de hundirse en el puerto de Mar del Plata, había deudas impagas con los proyectos de cooperación internacional y se le debía casi un millón de euros a distintos organismos a los cuales se les paga membresía, por lo que también internacionalmente nos habían dejado con muy mala imagen. A lo que se sumaba una comunidad científica que venía golpeada, que necesitaba un cambio de expectativas frente a cuatro años de maltrato. Esa fue nuestra primera misión: cambiar las expectativas. Nos pusimos a trabajar fuertemente en ello en los primeros meses de nuestra gestión y logramos las mejoras en las becas, duplicar los ingresos a la carrera del CONICET, aumentar los subsidios que estaba dando la Agencia Nacional de Promoción de la Investigación, el Desarrollo Tecnológico y la Innovación (Agencia I+D+i). Sorprendentemente había deudas, pero también había dinero de organismos internacionales, como el BID [Banco Interamericano de Desarrollo] o la CAF-Banco de Desarrollo de América Latina, que no se había gastado. Así que pudimos negociar con ellos cambios de destino. Fueron pequeñas señales para cambiar el estado de 
ánimo, para cambiar esa sensación de "mejor me voy, me están echando". Para mostrar un cambio de dirección y creo que eso lo logramos.

CTyP: La sanción de la Ley de Financiamiento del Sistema Nacional de Ciencia, Tecnología e Innovación debería posibilitar un incremento continuo del presupuesto en el sector hasta llegar al $1 \%$ del PBI en el 2032. Sin embargo, la sanción de una ley no es garantía de su cumplimiento, ¿qué dificultades prevén en su implementación?

RS: La ley 27.614 no sólo fue aprobada, sino que también fue promulgada por el presidente. Ahora estamos trabajando en su reglamentación y lo importante es que hay una sostenibilidad de ese gasto. De hecho, el pasaje del 0,25\% del PBI de 2020 al 0,28\% para este año y el incremento al 0,31\% para 2022, ya están contemplados en los respectivos presupuestos.

Cabe recordar que la inversión en I+D contempla diferentes componentes. Por un lado, la Función Ciencia y Técnica (FCyT), que es lo que el Estado nacional pone en el presupuesto todos los años. Por otro lado, una parte que corresponde a las Universidades, que no está incorporada en esa función (por ejemplo: salario de los profesores con dedicación exclusiva). En tercer lugar, el aporte de las provincias. Finalmente, las inversiones del sector privado, que históricamente han sido más o menos constantes en un valor del 0,15\% del PBI. Para dar una idea en el 2015 la inversión total en I+D era del $0,62 \%$ del PBI y la correspondiente a la FCyT era el 0,35\%. Durante el gobierno de Macri el total se redujo al $0,46 \%$ del PBI y la FCyT al 0,23\%. Ahí se ve el tremendo desfinanciamiento que ese gobierno produjo.1.2

Lo que nosotros pretendemos con esta ley es llevar la FCyT al 1\% del PBI al final de esta década, de modo que con los otros aportes podamos alcanzar un 2\% en I+D. Para tener una referencia, ese es el valor promedio de la Unión Europea. El aporte del sector privado se estimula mediante la Ley de Promoción de la Economía del Conocimiento, la cual otorga beneficios a las empresas de base tecnológica que hacen inversiones en investigación y desarrollo.

¿Qué garantías de cumplimiento de esta ley tenemos? En realidad, la única garantía es el éxito político de un gobierno que apueste al desarroIlo científico-tecnológico y que dé continuidad a proyectos basados en este tipo de políticas. Para ser claros, la única garantía, en definitiva, es que la sociedad y en particular la comunidad científico-tecnológica apuesten por aquellos proyectos políticos que creen realmente que la ciencia y la tecnología son una herramienta para el crecimiento y el desarrollo, y no apoyen a aquellos espacios políticos que plantean que el Estado es una carga y que, por lo tanto, hay que reducir las inversiones que realiza. Nuestro espacio político, hoy el Frente de Todos, en la etapa 2003-2015 Ilamado Frente para la Victoria, ha apostado siempre al desarrollo científico-tecnológico y eso tiene sus raíces en la época del primer peronismo, cuando el General Perón creó la Comisión de Energía Atómica, el Instituto Antártico, la Universidad Obrera, entre otros organismos de CyT. Siempre hubo en nuestro sector una impronta de desarrollo científico-tecnológico autónomo que retomamos en el período

\footnotetext{
1 Todas las notas al pie son agregados de los entrevistadores, incluidas con el fin de profundizar en el tema de cada pregunta y no reflejan necesariamente la postura del entrevistado.

2 Aliaga, J. (2019). Ciencia y tecnología en la Argentina 2015-2019: panorama del ajuste neoliberal. Ciencia, tecnología y política, 2(3), 024. https:// doi.org/10.24215/26183188e024.
} 
2003-2015, y ahora la volvemos a retomar.

Por otro lado, me gustaría remarcar que en términos políticos la aprobación de la ley fue una enorme derrota que el sector de CyT le infringió al modelo neoliberal periférico de Cambiemos. Porque la ley, en esencia, dice que el Estado tiene que invertir. Es decir, lo opuesto a su concepción política y a lo que hicieron, que fue reducir la inversión pública, achicar al Estado. Y tuvieron que apoyarla. Recordemos que fue votada prácticamente por unanimidad.

CTyP: Entre los cambios producidos en la estructura organizacional del Ministerio, se cuenta la descentralización de la Agencia I+D+i y la jerarquización del cargo de Presidente del CONICET a Secretaría de Estado. ¿Cuál es la finalidad de esas iniciativas?

RS: Por un lado, es un reconocimiento a una mayor jerarquía para la Agencia I+D+i que tenía algunas limitaciones en cuanto a su funcionamiento. Tenía una lentitud para operar y realizaba un trabajo de gestión muy burocrático. La descentralización lo que pretende es dar una agilidad mayor a la gestión. De hecho, se ha logrado. Durante la pandemia hubo un flujo de fondos con una dinámica que antes no había tenido. Los fondos llegaron rápido, dentro de lo que eran los parámetros habituales: desde que se comenzaba la presentación hasta que se recibían los fondos pasaba un año aproximadamente para recibir un subsidio. Y después había otras demoras. Logramos agilizar esta tarea, la Agencia trabajó muy bien. Y la descentralización sirvió para eso. Por otra parte, la Agencia I+D+i sigue trabajando dentro de la esfera política del Ministerio. Desde el MINCyT fijamos la política de todo el sistema de ciencia y tecnología de la Argentina y elaboramos el plan nacional de CyT. La ley de financiamiento, por caso, prevé que los gastos en el sec- tor se realicen en el marco del plan que elabora el Ministerio. Entonces, la Agencia y el CONICET trabajan en ese ámbito.

Por otro lado, la jerarquización del CONICET es un caso paradigmático. En otros organismos descentralizados el puesto de presidente o director son cargos de Secretario de Estado. El CONICET, con más de 25.000 personas, es uno de los organismos más grandes. Por lo que el cargo de subsecretario no era acorde con la responsabilidad que tiene la conducción de un organismo de semejante volumen. Así que, en ambos sentidos, se expresa una apuesta del gobierno hacia la ciencia y la tecnología, al igual que con la Ley de Financiamiento.

CTyP: Un aspecto crecientemente en discusión es el de la federalización de la ciencia y tecnología. ¿Cuál es la situación actual y qué medidas consideran necesarias en términos de descentralización y desconcentración? ¿Qué lugar piensan darle a los organismos provinciales y regionales de ciencia y tecnología?

RS: Cuando se mira la inversión en CyT por habitante según región, tomando 2019 como referencia, las regiones que peor están son el NEA y el NOA. Mientras que las que están bastante bien son la zona Centro y Cuyo. En cuanto a la Patagonia, hay disparidades porque tiene pocos habitantes y una gran inversión en zonas como Río Negro, por el INVAP y el Centro Atómico Bariloche. Pero si se mira hacia Santa Cruz o Tierra del Fuego hace falta poner más recursos ahí. Así que lo primero que debemos hacer es redistribuir recursos que están concentrados en la región centro del país. La Ley de Financiamiento estipula en el artículo ocho que el 20\% de los incrementos anuales estarán destinados a eliminar asimetrías regionales. Es decir, no se va a 
hacer un reparto indiscriminado de los mayores recursos, sino que estarán direccionados por una política.

Pero el financiamiento tiene que ir acompañado de otras medidas, como una mejor distribución de los recursos humanos. O sea, en simultáneo, hay que aumentar los recursos e implementar políticas para que se asienten investigadores en esas regiones. Haciendo planes con las universidades locales, con cada provincia, de modo que los núcleos de investigadores que se instalen en esos lugares estén diseñados para satisfacer las necesidades provinciales y tengan la infraestructura y recursos para que esos proyectos sean atractivos. Estamos pensando en grupos de trabajo interdisciplinarios donde participen la universidad, el INTA [Instituto Nacional de Tecnología Agropecuaria], el INTI [Instituto Nacional de Tecnología Industrial], el CONICET y los organismos provinciales, enfocados en temas prioritarios de la respectiva provincia. Por lo tanto, es imprescindible hacer partícipe a las provincias del diseño de esos Centros Regionales Científicos y Tecnológicos. Tenemos un plan ya aprobado y en marcha, con financiamiento de organismos internacionales como el BID y la $\mathrm{CAF}$, que contempla un programa de recursos humanos, uno de infraestructura y otro de equipamiento. La definición de las prioridades sobre las que se va a enfocar ese plan se va a dar en el Consejo Federal de Ciencia y Tecnología (COFECyT), en donde participan los secretarios de ciencia y técnica de cada jurisdicción. Por otro lado, el CONICET está armando un programa de federalización que ya ha establecido un acuerdo con la provincia de Entre Ríos, mediante el que se otorgaron a la provincia ochenta becas cofinanciadas y doce cargos de investigador. Apostamos además a promover que las universidades locales generen más doctores y que, a su vez, sea atractivo para algunos investigadores trasladarse y crear grupos. Si comparamos Entre Ríos con Santa Fe, que está al lado, hay una diferencia abismal. Ambas provincias están igualmente cerca de Buenos Aires. Pero Santa Fe tiene muchísimas más capacidades científicas que Entre Ríos. Eso es una asimetría que no se puede sostener. Y es solo un ejemplo.

\section{CTyP: El Ministerio ha anunciado la elabora- ción del Plan Argentina 2030, con un docu- mento de base para la discusión. ¿Qué acto- res consideran que deberían participar en su elaboración? ¿Tienen pensado algún meca- nismo y plazos para convocarlos? ¿Qué recu- peran y qué modificarían del Plan 2020?}

RS: Esta pregunta está muy ligada a la anterior porque creemos que, justamente, las demandas de las provincias tienen que estar en el plan nacional de ciencia y tecnología. Es decir, que las provincias se conviertan en un actor fundamental en la elaboración del plan. Por supuesto, estamos convocando a referentes de la comunidad, a representantes políticos y gremiales, organizaciones sociales y otros espacios. Pero hemos introducido algo que es realmente disruptivo: que la elaboración del plan sea hecha desde las provincias a partir de las metas regionales de desarrollo. Por ejemplo, ¿a qué va a estar apostando el NOA? ¿Al litio? El triángulo de Jujuy, Salta y Catamarca, ¿lo toma como prioridad? O el tema de las energías alternativas, eólicas en el caso de la Patagonia. La idea es poder definir con ellos una agenda, de cuáles son las propuestas para cada región y, después, en particular para cada provincia.

En este momento el Secretario de Planeamiento y Políticas, Diego Hurtado, está convocando y trabajando con los secretarios y autoridades provinciales para recoger esas demandas. No queremos tener un plan que sea elaborado por 
un grupo de referentes, fundaciones $u$ organismos. Queremos que esté traccionado por la demanda real. Y la demanda real sale de los planes de desarrollo de cada provincia, de cada lugar. El componente orientador del plan que va a definir las políticas que tiene que atender la Су $\top$ va a ser solucionar los problemas de nuestra sociedad en cada región. Para ello necesitamos saber cuáles son las apuestas locales y territoriales y cuáles son los problemas y demandas que la CyT puede contribuir a solucionar.

Toda esa articulación va a constituir un Plan Argentina 2030 que va a ser mucho más rico que el Plan 2020. El Plan 2020 fue un avance. Antes no había una planificación, fue un primer paso. Tenía algunas metas que estaban bien, pero también muchos defectos, como la distribución de recursos humanos. Cuando se analiza este aspecto en los organismos de ciencia y técnica que componen el sistema nacional, resulta que faltan investigadores en los organismos descentralizados que dependen de otros ministerios como el Servicio Meteorológico Nacional, el INTA, el INTI o el Instituto Antártico Argentino. En los próximos meses vamos a estar convocando a todos los actores y veremos si podemos llegar a fin de este año con un bosquejo de plan lo bastante maduro para presentarlo públicamente. $Y$ que sea un plan más rico, amplio y serio que el Plan 2020, con una concepción de la ciencia y la tecnología mucho más estructural.

CTyP: Contar con un plan estratégico aporta a darle coherencia a un sistema científico-tecnológico. Pero puede quedar en letra muerta si no se logra superar la fragmentación institucional. ¿Cómo piensan lograr una mejor articulación de los organismos de CyT? ¿Qué papel tendrá el Consejo Interinstitucional de Ciencia y Tecnología (CICyT) y el COFECYT?
RS: El COFECYT tiene un rol estratégico para garantizar el programa de federalización y revertir las asimetrías. Ahí vamos a discutir cómo se van a aplicar los fondos previstos en la Ley de Financiamiento. Algo ya dijimos al respecto.

En cuanto al rol del CICyT, hemos encarado un trabajo de fondo con la Secretaria de Gestión y Empleo Público a cargo de Ana Castellani, que es también investigadora en ciencias sociales y experta en el tema. Nos estamos sentando con cada organismo del complejo CyT para ver temas salariales, de estructura, cuál es su planta de personal óptima, cuántos recursos humanos tienen realmente dedicados a la investigación y qué necesitan esas instituciones para fortalecer lo que es I+D. Ya estamos trabajando, por ejemplo, con el Servicio Meteorológico Nacional, el INTA, el Instituto Antártico Argentino, el Instituto Nacional de Investigación y Desarrollo Pesquero [INIDEP], entre otros. Buscamos eliminar asimetrías salariales o de estabilidad laboral entre organismos. También estamos trabajando con CONICET en un plan de becas cofinanciadas para reforzar la planta de otros organismos.

Por otro lado, ambos consejos además tienen un papel importante en la articulación, para que el complejo CyT funcione realmente como un sistema, donde converjan las metas y objetivos de los diferentes organismos. Particularmente buscamos lograr una mejor coordinación con los organismos descentralizados que tienen misiones concretas y son efectores directos y que, en muchos casos, han sido maltratados, abandonados o tienen plantas envejecidas. Por ejemplo, el INTA que llega al productor, el INTI que trabaja directamente con la industria o el Instituto Nacional de Prevención Sísmica que impacta directamente en factores de riesgo. Queremos fortalecer estas instituciones, porque si podemos darles un impulso también vamos a mejo- 
rar la articulación con la sociedad. Si, además, desde las provincias recogemos las demandas regionales y las incluimos en la construcción del Plan 2030, vamos a tener una mejor articulación dentro del sistema CyT y con la sociedad. Esa es la idea.

CTyP: ¿Cómo evalúan la experiencia de la Unidad Coronavirus como una forma de enfrentar problemas concretos de la sociedad? ¿Qué lugar ocupará el financiamiento de proyectos orientados por demandas o misiones y la dinámica problema-solución en las políticas del MINCyT? ¿Podría replicarse con otros grandes problemas nacionales?

RS: La experiencia de la Unidad Coronavirus fue poner en marcha lo que nosotros teníamos en la cabeza: la idea de que era necesario una mejor articulación y trabajar en la resolución de problemas concretos. Salir del laboratorio y llegar a la sociedad. La apertura hacia afuera define objetivos, que no los ponemos los investigadores, sino que los pone la sociedad. En el caso del COVID-19 el objetivo era claro. Así que constituimos un núcleo flexible y dinámico que permitiera articular con el CONICET y las universidades. Teníamos, por un lado, los recursos humanos y la llegada territorial, y, por el otro, la Agencia I+D+i como financiador y al MINCYT como el gran articulador. Eso nos permitió salir con propuestas rápidas y llegar a la sociedad con soluciones. Pudimos establecer, en abril de 2020, la convocatoria a Ideas-Proyecto y de los cientos que se presentaron financiamos del orden de ochenta. Poco después lanzamos el Programa de Articulación y Fortalecimiento Federal de las Capacidades en Ciencia y Tecnología COVID-19, junto al COFECYT, donde también hubo cientos de proyectos de todo el país financiados.
Ese modelo de trabajo lo estamos replicando ahora con la Unidad Ciencia y Tecnología Contra el Hambre. Ahí, por ejemplo, estamos impulsando desarrollos tecnológicos en distintas universidades del país, con plantas pilotos que permitan poder desarrollar productos y asociarlos a cooperativas para que lleguen a los comedores.

En síntesis, hemos comprobado que estas unidades son excelentes para atención de emergencias y de problemas urgentes. Por otro lado, tenemos los proyectos estratégicos en los que se pone financiamiento para alcanzar un resultado: Ios proyectos orientados por misión ${ }^{3}$. Por caso, vamos a poner los recursos para terminar un prototipo para hacer una batería de litio que permita almacenar energía eólica. Otro ejemplo es el desarrollo del suero equino hiperinmune, en el que trabajó el ANLIS [Administración Nacional de Laboratorios e Institutos de Salud "Dr. Carlos Malbrán"], la Universidad Nacional de San Martín, el CONICET y las empresas BIOL e Inmunova.

Lo que vemos en ambos casos, solución de demandas urgentes o políticas estratégicas orientadas por misión, es que fomentan, además, toda la articulación de la que hablamos anteriormente. Cuando hay un objetivo o un problema concreto se da un autoensamblado, una articulación muy rápida. Y aparece además una épica. Contribuir a solucionar el tema del hambre o del COVID es muy convocante y nos hace articularnos espontáneamente porque son objetivos de trascendental importancia para el país y la sociedad.

Finalmente, quiero aclarar que además de focalizar nuestra gestión en la solución de problemas concretos de la sociedad, vamos a seguir financiando todo el sistema CyT, porque una

\footnotetext{
${ }^{3}$ Carrizo, E. (2019). Políticas orientadas a misiones, ¿son posibles en la Argentina? Ciencia, tecnología y política, 2(3), 027. https://doi.org/10.24215/26183188e027
} 
comunidad científica y tecnológica fuerte hace a nuestra propia capacidad de respuesta. Es lo que permite tener la base para luego ejecutar proyectos concretos generados por demandas sociales o estratégicas.

CTyP: Según la CEPAL nuestro país concentra su inversión en I+D en "investigación", centrado en la producción de artículos científicos, y destina muy pocos recursos al "desarrollo experimental" (producción nueva o mejorada de materiales, productos y procesos). Esta relación se invierte en los países que articulan la CyT con su economía y sus necesidades sociales. ¿Cómo hacemos para cambiar esta matriz cientificista?

RS: Si no se establece el vínculo con la sociedad, con la política y el Estado, no hay demanda. Al no tener demanda concreta es imposible que el investigador salga de su dinámica de generar conocimiento y publicarlo. Es lógico que busque publicar, porque la publicación es la manera que tiene el científico de poner a disposición su conocimiento. Pero ese tipo de conocimiento no sirve para establecer este vínculo que estoy planteando. Ese vínculo se establece en base a un diálogo con la sociedad y con el Estado. El Estado es el primer demandante de conocimiento a través de las políticas públicas. ${ }^{4}$ La demanda genera que parte de nuestra comunidad salga de un razonamiento como el siguiente: "como no tengo una demanda, estudio algo que está en la frontera de conocimiento". Eso tiene una lógica. El investigador busca trabajar sobre lo último que se sabe en esa temática. $Y$ eso nos sirve también, porque tenemos un científico entrenado en lo más avanzado. Entonces si frente a un problema concreto le decís a una investigadora que está haciendo investigación básica en dengue que deje eso de lado, y se ponga a trabajar en detección de anticuerpos contra COVID-19, y luego su trabajo culmina en el prototipo de un sistema de detección, que después se fabrica a gran escala y se usa durante la pandemia, resulta que le cambiaste la lógica. Esa investigadora hace poco decía: "no voy a volver a ser la misma". Esa frase marca lo que le pasó a una parte importante de nuestra comunidad científica. No volveremos a ser los mismos. Asistimos a un cambio de mentalidad en la relación entre ciencia, tecnología y sociedad, porque gran parte de nuestros científicos se vieron recompensados desde lo social. Y eso vale más para muchos de ellos que publicar un artículo en la revista Nature. Ahí hemos cambiado parte de la lógica. No está mal que investigadores que trabajan en áreas donde no hay demandas, quieran publicar en $\mathrm{Na}$ ture, y trabajen en la frontera del conocimiento, capacitando grupos de investigación, formando buenos doctores. Pero la demanda es la que genera ese vínculo con la sociedad. Entonces se trata de crear toda una telaraña de relaciones de ida y vuelta con actores sociales, con el Estado y con empresas, y establecer las demandas. Y que parte de nuestra comunidad científica esté abocada a trabajar en estos temas. Un buen ejemplo es el caso de los barbijos del CONICET. Las científicas y científicos que los desarrollaron venían trabajando con nanopartículas y rápidamente las adaptaron para actuar contra el virus y a usarlas impregnando las telas de los barbijos. $Y$ hoy vemos los barbijos del CONICET por todo el país. Yo creo que hay un clic en la mentalidad de muchos de nuestros científicos, pero también en la sociedad. Hemos empezado a darnos cuenta de cuánto vale la ciencia, cuánto vale en

\footnotetext{
${ }^{4}$ Acerca del papel del Estado como demandante de conocimiento, ver De Alto, B. P. (2020). Sustituyendo el futuro. Compras públicas de Tecnología para la Innovación. Ciencia, tecnología y política, 3(5), 045. https://doi.org/10.24215/26183188e045
} 
| Ciencia, Tecnología y Política | Año 4 | Nº6 | e051 | Mayo 2021 | ISSN 2618-3188 | www.revistas.unlp.edu.ar/CTyP |

lo social, en lo que hace al desarrollo y en lo que hace al bienestar y seguridad de los ciudadanos.

CTyP: Se ha señalado que nuestra producción científico-tecnológica es utilizada por empresas multinacionales que se sirven de ella para el desarrollo innovativo en sus países de origen y de la cual se apropian mediante derechos de propiedad intelectual. ¿Cómo frenamos esta extranjerización y privatización del conocimiento público?

RS: Cuando fui presidente del CONICET una de mis sorpresas fue enterarme que el organismo aparecía bien posicionado en los rankings de instituciones tecnológicas. ¿Cómo podía ser que una institución que estaba muy volcada a producir conocimiento básico estuviera bien en esos rankings? Entonces me informaron que ese indicador se construía contando cuántas veces era citada una institución en las patentes de invención. Pero las patentes no eran nuestras, eran patentes extranjeras que citaban artículos científicos hechos por investigadores del CONICET. Esto pone en evidencia nuestras limitaciones como país para apropiarnos del conocimiento que producimos. No es un problema de nuestros científicos. Es un problema del Estado argentino y de la sociedad que no es capaz de apropiarse de ese conocimiento y utilizarlo para nuestro beneficio. Esta utilización local va a ocurrir si nos ponemos a resolver problemas concretos. Mientras los problemas estén en abstracto, un investigador va a sacar un trabajo de muy buena calidad científica, lo va a publicar y va a quedar a merced de que lo utilice otro. Si logramos que nuestro sistema productivo y el propio Estado aprecien el valor que tiene ese conocimiento y las posibilidades de ser utilizado para generar productos con valor agregado y mejoras en nuestro desarrollo económico, nos va a permitir cambiar esa ruta. Nosotros quisié- ramos estar en los rankings por nuestra producción tecnológica, no por papers de ciencia básica que son citados en las patentes tecnológicas de Estados Unidos. Una mayor interacción entre la sociedad, incluyendo el sector empresario, el Estado nacional, provincial y municipal, y el entramado científico-tecnológico va a permitir que se nos escape menos el conocimiento. Voy a dar un ejemplo retomando el tema de los barbijos. El gobierno neoliberal de Macri había condenado al sector textil a desaparecer porque no era competitivo internacionalmente. Sin embargo, el sector textil se encuentra con el desarrollo de la nanotecnología. Y una PyME textil impregna con nanopartículas las telas para producir barbijos. Luego resulta que aparecen muchas más aplicaciones relacionadas con equipamiento médico y otros tipos de protección. Entonces, se abren un montón de perspectivas para una industria textil a partir de que se le da valor agregado con el aporte de la ciencia y la tecnología. No podemos ser competitivos con los textiles tradicionales, pero sí con materiales inteligentes. Diseño y valor agregado permiten textiles que sean autolimpiables, que sean repelentes de insectos, textiles especiales para las fuerzas armadas, etcétera. Así, se da una demanda concreta que va a permitir un crecimiento a PyMEs de base tecnológica en los próximos años a partir de la articulación entre ciencia, tecnología, producción, Estado y sociedad.

CTyP: En los países periféricos -e incluso en los centrales- ha sido el Estado el gran promotor de los desarrollos CyT. Además, en Argentina, la inversión privada en I+D siempre fue muy baja. ¿Qué política piensan desarrollar en relación con el rol del Estado y el sector privado nacional y transnacional? ¿Se promoverá la creación de empresas público-privadas? 
RS: Es cierto que históricamente la inversión privada no ha pasado del 0,11\% al 0,16\% del PBI, de acuerdo con cómo se mida. Nuestra apuesta para subir ese porcentaje es mediante la Ley de Promoción de la Economía del Conocimiento. Una normativa que tiene antecedente en la Ley de Promoción de la Industria del Software de 2004, un caso exitoso que permitió multiplicar la cantidad de trabajadores en el área de software y crear empresas chicas, medianas y grandes. Hay startups, que crecieron al amparo de esa ley, y hoy ya son "unicornios", es decir, superan el valor de mercado de mil millones de dólares. La Ley de Economía del Conocimiento de alguna manera extiende ese modelo a todas las actividades y junto a las exenciones fiscales son un aliciente para el incremento de la inversión privada. Hay sectores privados empresariales que tienen muy claro el rol de la CyT. Por ejemplo, la Cámara Argentina de Biotecnología, que sabe bien el valor de incorporar tecnología en una semilla o en un fármaco. Pero hay otros sectores que tienen menos capacidad para visualizar cómo ganan incorporando innovación en su producto. Entonces ahí hay todo un trabajo por hacer. Aquí aparece el trabajo de los vinculadores tecnológicos. Vamos a estar siguiendo paso a paso lo efectos de esta ley a través de las Encuestas de Innovación a cargo de la Dirección Nacional de Información Científica.

Por otro lado, está el tema de la creación de empresas mixtas con organismos de CyT. Teníamos varias previstas en 2015. Pero esos proyectos se cayeron durante el gobierno de Macri y hay que repensarlos. Hay dos experiencias que son de referencia para nosotros: una es Y-TEC y la otra es LA.TE. ANDES, ubicada en Salta. Esta última trabajó muy bien para Yacimientos Petrolíferos
Bolivianos durante la presidencia de Evo Morales. Hoy puede ser un buen socio de Y-TEC en trabajos de gas y petróleo en la región. En cuanto a Y-TEC ha crecido mucho. ${ }^{5}$ Incluso ha tenido un rol fundamental en la pandemia. Parece extraño que Y-TEC aparezca en un tema de salud. Pero cuando hubo que garantizar el sistema para poder producir los kits de diagnóstico de virus en el país, Y-TEC se encargó de poner la logística, de armar el mercado, el estudio de costos, la distribución y la importación de insumos. También colaboró con los laboratorios nacionales que realizan la producción. Un caso fue la solución a los problemas de puesta en marcha de un robot para producir los kits. Ahí la gente de Lubricantes de YPF resolvió esos problemas, porque ellos tenían experiencia en el manejo de estos sistemas robotizados. Incluso Y-TEC hizo parte de la inversión en ese laboratorio y hoy recuperó con creces esa inversión.

Otro ejemplo de articulación pública-privada se dio en el sector del software. Hubo empresas chicas y grandes que contribuyeron con la aplicación Cuidar. Eso se hizo en muy poco tiempo, en un trabajo articulado con la Fundación Sadosky, el MINCYT, las empresas y las cámaras empresariales de software. Tenemos, por lo tanto, un sector privado que se muestra más permeable a la inversión en innovación, un Estado que está apostando con una ley que da un incentivo fiscal y un sector CyT que busca esa vinculación. Aspiramos a armar un sistema científico-tecnológico-productivo que nos permita empezar a pesar en la región como exportadores. Pero no como un exportador de bienes primarios sino de productos con valor agregado.

\section{CTyP: La economía y producción popular es un sector que ha crecido en visibilidad y pre-}

${ }_{5}^{5}$ Sobre Y-TEC ver artículo de E. Dvorkin, en este mismo número de CTyP. Así como Bilmes, J. (2018). YPF-Tecnología (Y-TEC) y su rol en la política científico-tecnológica nacional. Ciencia, tecnología y política, 1(1), 010. https://doi.org/10.24215/26183188e010 
| Ciencia, Tecnología y Política | Año 4 | Nº6 | e051 | Mayo 2021 | ISSN 2618-3188 | www.revistas.unlp.edu.ar/CTyP |

sencia institucional. Como se ha señalado se caracteriza por una baja calificación técnica e intensidad tecnológica. ¿Desde el MINCyT se piensa desarrollar políticas específicas de vinculación y transferencia de tecnología a este segmento de la economía?

RS: Acabamos de firmar un convenio con el Ministerio de Desarrollo Social para transferir grupos de investigadoras e investigadores y orientarlos a resolver problemas concretos de este sector. Es un convenio marco. Necesitamos sentarnos y ver cuáles son las demandas. El extensionismo universitario podrá aportar mucho en esto, es un sector con el que se viene articulando hace mucho. Está trabajando además con nosotros Enrique Martínez y su grupo en los Parques de Producción Social, que serían parques tecnológicos pensados para la interacción con el sector de la economía popular y cooperativas. Es un sector con problemáticas diversas. En la agricultura familiar, que tiene una gran importancia económica, hay mucha precariedad laboral y dificultades en la comercialización para poder llegar directo al consumidor abaratando los productos. También está el tema del manejo de agroquímicos. En el caso de las cooperativas un ejemplo positivo ha sido el de la que está fabricando los test de anticuerpos rápidos. Los trabajadores de un laboratorio fundido durante el gobierno de Macri crearon esa cooperativa, que, articulando con investigadores de la Universidad Nacional de La Plata y del CONICET, lograron un producto con valor agregado. Es un ejemplo que podríamos replicar con otros actores y en otros lugares del país. Hay múltiples aristas, lo importante es abrir esa interacción entre economía popular y sistema de ciencia y tecnología. ${ }^{6}$
CTyP: El programa imPA.CTar se propone promover proyectos de investigación y desarrollo dirigidos a encontrar soluciones a demandas de organismos públicos del Estado, como ministerios, empresas públicas, gobiernos provinciales y municipales, entre otros. ¿Cuál es su estado de implementación y qué proyectos está llevando adelante?

RS: Tenemos muchas expectativas con el programa imPA.CTar. Está recién lanzado. Fue diseñado para tener una interacción directa con el nivel más territorial que son los municipios. Se trata de poder darle una herramienta al intendente para que venga y pregunte: "tengo este problema, ¿cómo lo soluciono?". Ahí aparece la necesidad de traducir eso a un problema tecnológico. Si encontramos que tiene aparejado algún componente de investigación, tecnología o innovación, intervenimos. Para nosotros innovación es innovación en el país, de modo que, si el problema no está resuelto en el país, aunque esté resuelto en otro lugar del mundo, estaremos innovando. En este momento se están considerando unos veinte proyectos y ya hay algunos que están aprobados. Puedo mencionar, como ejemplo, un proyecto con el Instituto Geográfico Nacional, que tiene como objetivo el relevamiento municipal a través de drones. $O$ el asesoramiento a un municipio para un mejor ordenamiento territorial o para enfrentar alguna especie invasora que les está causando daños.

CTyP: ¿Cuál es el estado de la iniciativa Pampa Azul? ¿Cómo la encontraron al asumir? ¿Cómo piensan articular esta iniciativa con la cuestión de la soberanía marítima y antártica y la reivindicación de las Islas Malvinas, Sándwich y Georgias del Sur?

\footnotetext{
${ }^{6}$ Al respecto puede consultarse Martínez, E. M. (2020). Economía popular, producción popular y desafíos tecnocientíficos. Ciencia, tecnología y política, 3(5), 042. https://doi.org/10.24215/26183188e042
} 
RS: El proyecto Pampa Azul nació en 2014 y al año siguiente se aprobó la Ley Promar creando el Programa Nacional de Investigación e Innovación Productiva en Espacios Marítimos Argentinos.? Mediante esta ley había fondos asignados. Pero a partir del cambio de gobierno, el Pampa Azul quedó prácticamente desmantelado. Durante el gobierno anterior se hizo muy poco. Llegaron dos barcos que fueron incorporados al INIDEP: el Buque Víctor Angelescu y el Buque Mar Argentino. El financiamiento para estas dos importantes compras se inició en 2015. Y eso no se discontinuó, así que esos barcos llegaron. Pero el proyecto en general quedó paralizado. Uno de los ejemplos más claros es el estado deplorable en el que encontramos a los buques Austral y Puerto Deseado, los barcos del CONICET. No se invirtió en su mantenimiento. El año pasado se ha retomado el trabajo iniciado en 2015 con la convocatoria a una reunión del Consejo de Administración del PROMAR. Por otro lado, la iniciativa ya tiene un presupuesto que, dentro de lo que permitió la pandemia, es relativamente importante. Son unos 230.000.000 \$ AR que se van a destinar fundamentalmente a reparación, a equipamiento de los buques y a realizar equipamiento costero en diferentes áreas. Por otro lado, y por fuera de ese presupuesto, estamos trabajando en varios proyectos interinstitucionales en toda la línea costera en los que se trabaja sobre el conocimiento del mar, la biología marina, los recursos energéticos, etc. Por ejemplo, en Mar del Plata va a estar trabajando el INIDEP, el CONICET, la Universidad Nacional de Mar del Plata y el Servicio de Hidrografía Naval. En Ushuaia, además, estamos planteando la creación de una subsede del Instituto Antártico Argentino. ${ }^{8}$ Esos centros interinstitucionales los vamos a estar financiando con fondos internacionales para crear toda una red de anclaje y de logística para la investigación oceanográfica de los barcos. Por eso en la zona costera vamos a reforzar las tomas de datos que ya están instaladas. Recordemos que en Argentina solo el 1\% del PBI proviene de recursos marítimos. Eso es inexplicable en un país que tiene un litoral marítimo tan extenso. Así que hay que trabajar fuertemente, por un lado, para potenciar estos recursos y, por otro lado, como una forma de afianzar nuestra posición en la disputa de la soberanía. Recuerdo que nuestros investigadores en biología defendían que las Islas Malvinas son claramente territorio nacional mostrando que las especies biológicas que están en las islas son las mismas especies que están presentes en el litoral argentino. Entonces hay una continuidad desde el punto de vista biológico. Es solo un ejemplo de cómo desde lo científico se puede reforzar la pretensión de soberanía de nuestro país sobre las islas.

\section{CTyP: Durante su presidencia en el CONI-} CET se hicieron cambios como la incorporación de los temas estratégicos y la creación de empresas como Y-TEC. En esta etapa, ¿qué medidas se proponen desarrollar para el CONICET? ¿Creen necesario revisar las políticas de evaluación del organismo?

RS: El CONICET es un organismo autárquico, descentralizado. Desde el MINCYT lo que hacemos es trazar los grandes lineamientos de la política científica del país y eso incumbe a todos los organismos y, por supuesto, al CONICET. Esta institución tiene que revisar cla-

7 Sobre el Pampa Azul, ver Sala, J. E. (2018). Pampa Azul: el mar como territorio. Ciencia, tecnología y política, 1(1), 006. https://doi.org/10.24215/26183188e006

${ }^{8}$ Sobre la política científica argentina respecto a la Antártida, ver en este mismo número de CTyP el artículo de Mariano Memolli. 
| Ciencia, Tecnología y Política | Año 4 | Nº | e051 | Mayo 2021 | ISSN 2618-3188 | www.revistas.unlp.edu.ar/CTyP |

ramente su política de evaluación. Cuando fui presidente del CONICET en 2012 había investigadores que querían abandonar el organismo porque no les aprobaban los informes. Hacían investigación aplicada o desarrollo experimental y, como no tenían muchas publicaciones, los rebotaban. Entonces surgió la idea de los Proyectos de Desarrollo Tecnológico Social (PDTS), en conjunto con el MINCYT, las universidades y otros organismos de CyT. Se trataba de implementar una evaluación diferente. En 2015 se comenzaron a ejecutar y luego ya no se hizo nada. Y siguió pasando que, por caso, a investigadores de CONICET en Y-TEC, una empresa de base tecnológica, la Comisión de Tecnología los evaluaba por sus publicaciones. Eso desalienta a los jóvenes a hacer tecnología y no puede volver a ocurrir. Estamos trabajando con la presidenta del CONICET, Ana Franchi, en ese sentido. Sino ¿qué vamos a hacer con los investigadores que desde que comenzó la pandemia dejaron lo que estaban haciendo para contribuir, en muchos casos exitosamente, en proyectos y desarrollos vinculados al COVID? ¿Qué le van a decir de sus informes? ¿Que no publicaron? Tenemos que aprovechar este momento en el cual no puede haber una sola voz que se alce en contra de que estos cambios se implementen. Porque hay sectores de la comunidad CyT que son muy conservadores. Dicen que quieren cambiar, pero cuando van a una comisión hacen lo contrario: jempiezan a contar publicaciones! 9 Para que quede claro: está bien que, si una persona está trabajando en ciencia básica, haga buena ciencia y publique. Pero quienes están trabajando en proyectos sobre demandas apli- cadas deben ser evaluados de otra manera, analizando lo que hicieron en el proyecto, sus resultados, su impacto. Las comisiones de evaluación lo tienen que considerar y es este el momento. Quiero aclarar que no es un debate que se da solo en Argentina. En la ciencia mundial está en discusión la presión por publicar. Los temas que el Estado define como prioridades deben tener otra lógica de evaluación. Hay que darle las condiciones a los investigadores que participan en ellos para trabajar tranquilos, para que puedan concretarlos exitosamente y tener el reconocimiento que se merecen. Imagínense que a los científicos rusos o norteamericanos que estaban en la carrera espacial... jles hubieran pedido publicaciones! Hay otras maneras de evaluar. Ahora es el momento. Si no somos capaces ahora de hacer ese cambio en los criterios de evaluación nos vamos a arrepentir por mucho tiempo..$^{10}$

\section{CTyP: En la Comisión Nacional de Activida- des Espaciales (CONAE), ¿qué políticas se proponen impulsar para los próximos años? ¿Qué pasará con el desarrollo de sistemas de lanzamiento de cohetes Tronador y la em- presa VENG? ¿En qué estado se encuentra la creación de la Agencia Espacial Regional de América Latina y el Caribe?}

RS: La CONAE ha tenido este año un muy buen presupuesto comparado con años anteriores y tiene en elaboración el plan espacial, que incluye el programa de lanzadores. En cuanto a satélites, lo más inmediato es el Satélite Argentino Brasileño para Información del Mar (SABIA-Mar), pero hay que ver si el gobierno de Brasil sigue apostando a ese proyecto. Nosotros lo vamos

\footnotetext{
9 Sobre el papel de las publicaciones en la evaluación del CONICET, ver Cano, M. E., Chuchuy, A., y Unzurrunzaga, C. (2020). El valor de la producción científica y del paper para ingresar a la carrera de investigador del CONICET. Ciencia, tecnología y política, 3(5), 049. https://doi. org/10.24215/26183188e049

10 Sobre los criterios de evaluación científica, ver Cátedra Libre Ciencia, Política y Sociedad. (2019). La evaluación en ciencia y tecnología en Argentina. Estado de situación y propuestas. Ciencia, tecnología y política, 2(3), 025. https://doi.org/10.24215/26183188e025
} 
a continuar. Se está avanzando incluso con la compra de partes del satélite. Por otro lado, impulsado por la Comunidad de Estados Latinoamericanos y Caribeños (CELAC), estamos discutiendo un proyecto de desarrollo de un satélite meteorológico latinoamericano. Este proyecto sería financiado por el BID. Argentina construiría el satélite, ya que es quien tiene la capacidad en Latinoamérica de hacer este tipo de desarrollos. Desde el punto de vista diplomático está bastante avanzada la idea, al igual que con la Agencia Espacial Latinoamericana. Sin embargo, como la región ha sufrido vaivenes geopolíticos, hay que volver a indagar sobre el interés del resto de los países en estos proyectos. Pero, en principio, al menos para el SABIA-Mar y el satélite meteorológico de la CELAC, hay apoyo.

En cuanto al tema del acceso al espacio, fue dejado de lado durante el gobierno anterior. VENG, la empresa que debía encargarse de la construcción de los vehículos, por decisión de Macri fue orientada a vender las fotografías del satélite SAOCOM. ¡Eso es lo que había quedado de VENG! Ahora con esta empresa estamos retomando el programa de acceso al espacio. Queremos avanzar con los lanzadores, lo que significa poner la infraestructura de vuelta en marcha, ya que quedó todo muy abandonado. "

\section{CTyP: Al igual que en otros ámbitos el "techo de cristal" en la carrera científica es una limi- tación que afecta fuertemente a las mujeres. Lo cual se evidencia en que los escalafones más altos de la actividad científica siguen siendo ocupados por hombres. ¿Qué políticas está desarrollando el MINCyT en relación con la problemática de género?}

RS: Tenemos un programa de género que fue el primero que validó el Ministerio de la Mujer, con muy buena repercusión. Inclusive está siendo usado de modelo por otras áreas. El programa básicamente tiende a corregir dos aspectos. En ciencia, Argentina no está mal en participación de la mujer. De hecho, el CONICET tiene un reconocimiento de la UNESCO por ser la institución con más participación de la mujer en la ciencia. Tenemos ahí un 53\% de mujeres y un $47 \%$ de hombres, situación que estaba invertida en el 2001. Sin embargo, las mujeres tienen poco acceso al financiamiento comparado con los hombres. Acceden a más proyectos, pero el financiamiento global obtenido es menor. Entonces, en primer lugar, tenemos que trabajar sobre las causas que provocan esta desigualdad. En segundo lugar, sobre el "techo de cristal". El hecho de que hay pocas mujeres en cargos directivos y en los escalafones más altos de la carrera. En este punto hay que mirar también lo que ha sucedido en el tiempo. En 2003 teníamos aproximadamente un 35\% de mujeres que eran investigadoras independientes. Hoy prácticamente la mitad de las investigadoras están en la categoría independiente. En investigadores superiores había solamente un 10\%. Hoy está en el orden del $15 \%$ al $20 \%$. Es un movimiento favorable. $Y$ hay que acelerar ese movimiento en la participación en cargos directivos. Para lograr una mayor igualdad vamos a hacer un seguimiento actuando sobre los mecanismos que generan la desigualdad. Por ejemplo, lo que ya se está haciendo en convocatorias de la Agencia I+D+i, donde se está considerando una participación equitativa en género. $Y$ en cuanto al ascenso en la carrera científica la manera más clara de avanzar es tener en las comisiones evaluadoras un mayor porcentaje de mujeres. $Y$ pedirles a aque-

\footnotetext{
11 Para un panorama sobre el sector espacial argentino, ver Sabando, Sarmiento y Hough (2019). Un análisis de la tecnopolítica aeroespacial argentina. Ciencia, tecnología y política, 2(2), 022. https://doi.org/10.24215/26183188e022
} 
| Ciencia, Tecnología y Política | Año 4 | Nº | e051 | Mayo 2021 | ISSN 2618-3188 | www.revistas.unlp.edu.ar/CTyP |

llas investigadoras que integran las comisiones que tengan también una actitud proactiva de garantizar que haya equidad en esas evaluaciones.

Por último, quiero destacar que la pandemia puso en relieve el rol de la mujer en la ciencia. La mayoría de los desarrollos que llegaron a la sociedad fueron encabezados por equipos de mujeres. El caso de los barbijos por Silvia Goyanes y Ana Maria Llois o el caso del test COVIDAR por Andrea Gamarnik. Así como la vacuna que estamos intentando desarrollar que está cargo de Juliana Cassataro. ${ }^{12}$

CTyP: La cooperación internacional supone tanto una potencialidad como un riesgo. Sirve al avance de la ciencia local, pero al mismo tiempo puede hacernos dependientes de la agenda científica internacional. ¿Qué políticas piensan implementar para que la cooperación signifique un avance para nuestro país y no una integración subordinada?

RS: Lo primero que hay que tener en cuenta es que arrastramos convocatorias hechas previamente y eso no se puede modificar. Ahora hay que trabajar en adelante con la mirada del Plan 2030. Ahí estarán definidas las prioridades nacionales. Entonces, de acuerdo con esos objetivos, vamos a focalizar la cooperación internacional. Luego, hay que distinguir dos tipos de cooperación. Una de tipo tradicional o clásica con países centrales como Alemania, Estados Unidos o Francia. Es una cooperación respetable, que a Argentina le ha servido de mucho para poner en valor su ciencia. Pero hay que ir perfilándolas hacia donde nuestro país quiere apostar. Lo que estamos haciendo ahora es de- finir cuáles son los temas que queremos trabajar con cada país, buscando temas que puedan ser de interés para ambas partes, y no solo para una de ellas. ${ }^{13}$ En segundo lugar, está la cooperación regional. Hay que decir que no hemos logrado fortalecer esta cooperación en nuestra historia. No hay mucha interacción con nuestros colegas de México o de Bolivia. Un poco más con Chile o Brasil. Pero hay que potenciar esa cooperación y para eso, para tener una integración regional mayor se requiere coincidencias políticas con la región. Es muy difícil, salvo en casos puntuales, avanzar cuando no tenemos un marco de referencia conjunto hacia donde queremos ir. Por ejemplo, con Bolivia nos proponemos una cooperación en el área de litio, gas y petróleo. Vamos a ver si nuestros colegas de Bolivia tienen el mismo interés que nosotros en trabajar en forma cooperativa. Pero estamos proponiendo enfocarnos en esos nichos. ${ }^{14}$

\section{CTyP: China se está consolidando como una} gran potencia mundial, desplazando la supremacía de los Estados Unidos, y es un gran socio comercial y fuente de inversiones para nuestro país. Uno de los factores que explican su crecimiento ha sido una sólida política CyT. ¿Qué podemos aprender de la experiencia china? ¿Qué políticas están pensando en el Ministerio en relación con ese país?

RS: Estamos trabajando activamente con la embajada argentina en China potenciando varios temas que ya teníamos en curso. Por ejemplo, en un acuerdo en el marco de la Ruta de la Seda, sobre producción de alimentos pecuarios y porcinos. También en temas de biotecnología. Por

\footnotetext{
12 Para más detalles ver Franchi, A. M. (2019). Las mujeres y la ciencia: obstáculos y desafíos para lograr la equidad de género. Ciencia, tecnología y política, 2(3), 026. https://doi.org/10.24215/26183188e026

${ }^{13}$ Respecto a esta cooperación tradicional, ver: Feld, A., y Kreimer, P. (2020). Latinoamericanos en proyectos europeos: asimetrías en la cooperación científica internacional. Ciencia, tecnología y política, 3(4), 035. https://doi.org/10.24215/26183188e035

${ }^{14}$ López, M. P. (2020). Cooperación en biotecnología aplicada al desarrollo de vacunas y fármacos entre Argentina y Cuba (2009-2015). Ciencia, tecnología y política, 3(4), 038. https://doi.org/10.24215/26183188e038
} 


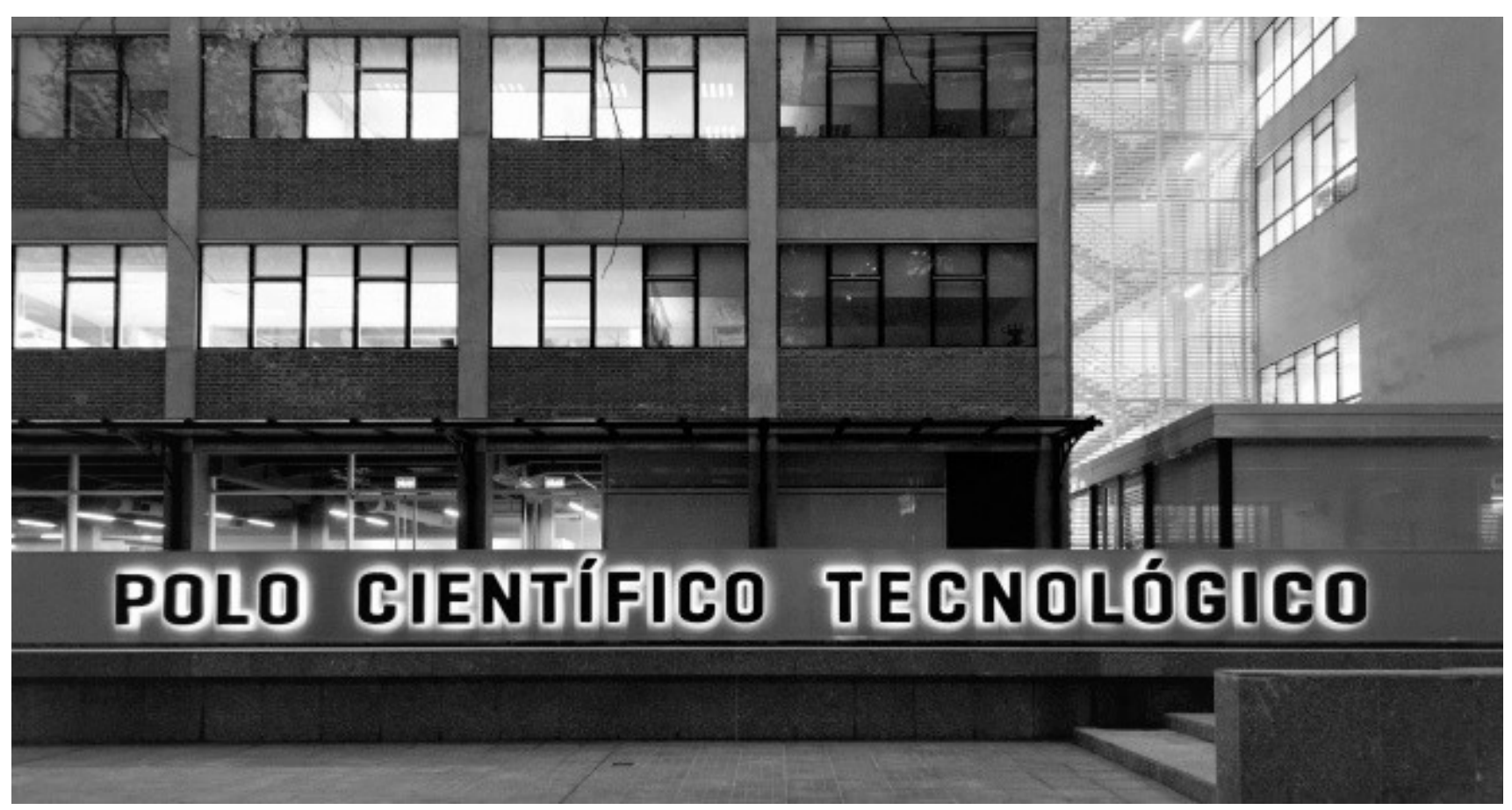

otro lado, en el área espacial, China tiene instalada una antena en Neuquén, en el marco de una cooperación científica, en la que se trabaja en investigación del espacio profundo. También estamos colaborando en el desarrollo de un radiotelescopio muy importante, llamado CART, que se va a instalar en San Juan. Y en la misma provincia se instalará un centro de cooperación bilateral entre la Academia de Ciencias de China y el CONICET. Un tema que a nosotros nos interesa es el de las imágenes satelitales. ¡No puede ser que Chicago conozca nuestra producción de soja antes que nosotros! Nosotros obtenemos información para el agro a través de las imágenes de radar que brinda el SAOCOM, pero China tiene satélites de observación con mucha mayor resolución. De modo que China es un buen socio en ese sentido para mejorar nuestra capacidad satelital.

En cuanto a qué se puede aprender de China hay varias cosas. Por un lado, algunas pautas muy importantes para el desarrollo tecnológico a partir de la instalación de empresas. El polo tecnológico de Pekín es impresionante. Tiene veinte mil empresas extranjeras nucleadas alrededor de una universidad que le da sustento: la Universidad de Pekín. En Argentina hay algunas ciudades que tienen las condiciones para algo similar. Por ejemplo, Córdoba, que cuenta con una Universidad Nacional, el clúster de informática, una industria aeronáutica, la Fábrica Argentina de Aviones (FAdeA) y el Laboratorio de Hemoderivados. ${ }^{15}$ Se podría pensar en instalar un polo tecnológico con muchas empresas alrededor de estas capacidades tecnológicas y de recursos humanos. No se trata de que se instalen empresas para que desarrollen tecnología y después esa tecnología se exporte o se instale como una caja negra. Sino que hay que aprender de esa tecnología. Hay que aprender de China en esos acuerdos, la manera de ir apropiándose de esa tecnología, de lograr la transferencia tecnológica. ${ }^{16}$

\footnotetext{
${ }_{15}$ Sobre este último puede consultarse Díaz de Guijarro, E. (2019). Laboratorio de Hemoderivados de Córdoba: modelo de producción pública de medicamentos. Ciencia, tecnología y política, 2(3), 030. https://doi.org/10.24215/26183188e030

${ }^{16}$ Al respecto puede consultarse el artículo de Haro Sly y Liaudat en este mismo número de CTyP, así como Haro Sly, M. J. (2019). La política científica y tecnológica de China y la cooperación sino-argentina. Ciencia, tecnología y política, 2(3), 029. https://doi.org/10.24215/26183188e029
} 
CTyP: La problemática ambiental es un área que demanda una participación más efectiva de la CyT. No solo para la resolución de controversias sociales o judiciales, sino como política de estado en relación con aspectos de preservación de recursos, calidad de vida y soberanía. ¿Qué política se propone llevar adelante el MINCyT en este ámbito?

RS: En las temáticas ambientales el rol primario del Ministerio en esta etapa es centralmente técnico, en el sentido de brindar toda la información científico-tecnológica necesaria para la toma de decisiones. Por un lado, para el propio Estado, para la elaboración de políticas públicas. Por otro lado, para la sociedad y los actores involucrados. Por ejemplo, si se va a hacer un emprendimiento en determinado lugar y tiene un impacto ambiental, lo que pretendemos es que la evaluación pueda ser hecha con todas las capacidades que tiene hoy el sistema de CyT. O sea, ser un proveedor de información de calidad para la toma de decisiones. Por otra parte, percibimos que el sistema científico tecnológico puede actuar en calidad de mediador e incluso con la capacidad de ser garante. Por ejemplo, hoy en día hay un debate muy profundo en varias provincias por el tema de la minería. Es el caso de Mendoza y Chubut, donde no hay licencia social para ciertos emprendimientos y varios organismos de CyT se manifestaron en contra de estos, como el CENPAT-CONICET [Centro Nacional Patagónico], el INTA o la Universidad Nacional de la Patagonia San Juan Bosco. La sociedad tiene un cierto respeto y valoración del sector científico y esa aceptación puede permitir mediar y garantizar que ciertos mecanismos como un debate con todas las voces se lleve a cabo con la información correcta. Creo que, en cierto sentido, se nos puede ver como un árbitro. Lo cual también es complejo. Pero hay algo que quiero dejar en claro: nuestra posición es que sin licencia social no hay proyecto que pueda avanzar. Y la búsqueda de la licencia social lleva tiempo y a veces la política no da esos tiempos. Eso nosotros no lo podemos subsanar.

CTyP: Teniendo en cuenta que las principales actividades productivas con las que nuestro país espera obtener divisas son extractivistas y muy contaminantes (monocultivo de soja transgénica, megaminería metalífera, hidrocarburos no convencionales). ¿Cuál debería ser el papel de la CyT en relación con estas actividades?

RS: Hoy en día Argentina tiene un consumo de agroquímicos en exceso comparado con otros países. Necesitamos, en primer lugar, hacer el inventario, un mapa de esos agroquímicos y proponernos una meta de reducción. Por otro lado, hay actualmente un control cada vez más severo de trazas de agroquímicos en las exportaciones. La Unión Europea nos va a poner una barrera tecnológica para poder ingresar los productos que queramos exportar. Estamos integrando la Red de Monitoreo de Agroquímicos con la participación de todas las universidades de la zona núcleo, con el INTA y el CONICET. Nuestra idea es construir un mapa de la misma manera que se hizo con el Plan Nacional AccionAr, ${ }^{17}$ armar protocolos y decidir qué y cómo vamos a medir. Con esta red estamos construyendo el inventario de agroquímicos. Hemos convocado a grupos que son absolutamente críticos del uso de agroquímicos y a otros que son más favorables, que tienen una visión más productivista. Todos van a trabajar juntos. Creemos que lo que va a salir de ese monitoreo va a ser algo real, algo

\footnotetext{
${ }^{17}$ Se refiere al plan desarrollado por el Consejo Nacional de Coordinación de Políticas Sociales de la Presidencia de la Nación a través de la Subsecretaría de Políticas Sociales que permite hacer el seguimiento de la situación alimentaria de dos millones de niños.
} 
que va a tener un impacto para poder tomar decisiones sobre qué es lo que tenemos que hacer en cada lugar. También estamos trabajando en la Ley de Fitosanitarios, que va a permitir tener información acerca de qué está utilizando cada productor y poder hacer una trazabilidad.

En el caso de gas y petróleo creemos que hay que trabajar fuertemente en hidrógeno y litio y pensar en la electromovilidad. La idea es ir sustituyendo los combustibles fósiles con energía renovable, área donde la Argentina ha crecido en este último tiempo. Para dar una idea actualmente la matriz energética eólica y solar ha superado a la nuclear. Hay que avanzar en esta dirección, con mayor integración de la industria nacional. No se trata de comprar un parque eólico llave en mano. Acá se tienen que construir los molinos, y si este año no podemos construir al $100 \%$ empecemos con el 10\%, el año que viene pongamos la meta del 20\% y luego el 50\%. Y así, ir integrando la industria nacional.

En la cuestión ambiental, como pensaba Néstor Kirchner, no somos deudores, somos acreedores ambientales. Hoy en día pagamos el costo de los países centrales, que nos imponen las mismas condiciones que a los demás, cuando en realidad contaminamos durante siglos mucho menos que ellos. Nos dicen que nuestra contribución al efecto invernadero viene de la ganadería, con la emisión de metano. Pese a todo, la Argentina firmó el Acuerdo de París que nos obliga a reducirlo. $Y$ el financiamiento externo, los créditos del Banco Mundial o del BID, están condicionados al cumplimiento de esos acuerdos.

Por otro lado, tenemos una realidad actual con provincias productoras de petróleo y provincias que viven de la agroindustria. Entonces hay que caminar hacia una transición. No hay duda de que la meta es reducir gases, reducir agroquímicos y todo lo que tenga un carácter contaminante. Pero eso requiere un trabajo muy delicado y metas. No podemos cambiar la matriz actual con prohibiciones. Lo que tenemos que hacer es una transición hacia una matriz productiva menos contaminante.

CTyP: La comunicación pública de la ciencia es reconocida como una herramienta relevante en las políticas públicas de CyTy la pandemia, sin duda, lo ha puesto de manifiesto. Sin embargo, como lo describe una especialista en el tema, parece quedar siempre "en el fondo del ropero". ¿QQué lugar le asignan en las políticas del Ministerio?

RS: La pandemia nos permitió poner a la comunidad científica en acción y la comunicación de la ciencia se ha vuelto muy necesaria en un momento en que la irracionalidad parece predominar. Hay algunos grupos, sobre todo ligados con sectores de derecha, que tienen visiones absolutamente absurdas y rechazan las vacunas. Esto hace que parte de nuestro discurso se vuelva hoy esencial, como lo han demostrado infinidad de científicas y científicos que han tenido que salir a desmentir falsas noticias. Inclusive hay un grupo del CONICET que se encarga específicamente en ese trabajo. En lo personal este ministro pasa horas dando entrevistas públicas que van desde un pequeño medio del interior del país hasta grandes medios de ámbito nacional. Lo hacemos porque creemos que tenemos que comunicar, tenemos que explicar. Para nosotros eso es muy importante. Por otro lado, hemos estado trabajando mucho este

\footnotetext{
${ }_{18}$ La expresión proviene de Murriello, S. (2020). Comunicación pública de la CyT, ¿en el fondo del ropero? Ciencia, tecnología y política, 3(5), 046. https://doi.org/10.24215/26183188e046
} 
año con la Red Argentina de Periodismo Científico, con quienes hemos hecho ya tres reuniones para intercambiar información y elaborar propuestas. También estamos avanzando en consolidar todas las actividades del Centro Cultural de la Ciencia C3. Por otro lado, estamos trabajando por la vuelta de Tecnópolis. La idea es hacer un relanzamiento con todo. Obviamente va a depender de la pandemia. Nos hemos reunido con el Ministro de Cultura, Tristán Bauer, para coordinar acciones. Estamos trabajando en muchos proyectos que incluyen producción nacional y pandemia, vacunas, temas ambientales, el Pampa azul, el tema espacial... y vamos a estar convocando a los científicos para que participen. Es una propuesta muy ambiciosa y esperamos poder lanzarla en la segunda parte del año.

CTyP: El pago de suscripciones a revistas científicas por valor de varios millones de dólares representa una carga significativa sobre el presupuesto del MINCyT. Mientras tanto en el mundo viene creciendo la resistencia al oligopolio de las editoriales científicas: hay países que han roto acuerdos o contratos con editoriales, otros fomentan el acceso abierto, otros incluso promueven vías de acceso ilegal como Sci-Hub. ¿Cuál es la política del MINCyT al respecto?

RS: La Biblioteca Electrónica de Ciencia y Tecnología (BECYT) tiene efectivamente un componente presupuestario muy grande. Lo que hemos hecho fue renovar la suscripción logrando la condonación casi completa de la deuda que había, ya que no admitimos esa deuda. Y lo hemos conseguido con apoyo internacional. Pero sabemos que es una carga muy grande y que vamos a tener que decidir si la va a enfrentar el Estado Nacional. No podemos seguir pagando con fondos internacionales esas suscripciones.
Creemos que este es un tema que hay que discutir dentro de la comunidad, donde la opinión no es unánime. Desde secretarios de CyT de universidades que piden ser incorporados a la BECYT, hasta quienes piensan que hay que dejar de pagar este servicio y usar Sci-Hub. Resolver que no vamos a tener más biblioteca electrónica complicaría el trabajo de muchos grupos de investigación y, desde el punto de vista de la imagen de Argentina, también sería un problema. Si se va a mantener o no la BECYT tiene que debatirlo la comunidad y sacar una conclusión y en función de eso avanzaremos. Personalmente creo que vamos a ir hacia una transición. No podemos hacer cambios en forma disruptiva. Por otro lado, me parece muy importante el documento que está preparando al respecto el Comité Asesor Internacional en Ciencia Abierta de la UNESCO, donde tenemos participación. Próximamente vamos a ver las contribuciones que está haciendo ese organismo sobre el tema. Como ven, este ministro no les puede dar todas las respuestas necesarias. Pero sí marcar políticas, explicitar el rumbo hacia donde queremos ir. ${ }^{19}$

CTyP: Para terminar, ¿coincidís con la idea de que la crisis mundial y la pandemia nos abren la oportunidad para hacer una ciencia y una tecnología situadas, con nuestra propia agenda y puesta a resolver nuestras necesidades en términos de desarrollo, equidad y soberanía?

RS: Absolutamente. Insisto: es el momento. Para la Argentina es una gran oportunidad, porque estamos asistiendo a un cambio de mentalidad, y la sociedad nos acompaña. Se percibió que los científicos tienen un rol. También la política nos acompaña. Tenemos que aprovechar esta oportunidad. Diría que la ciencia y la tecnología nacionales están en un momento histórico.

\footnotetext{
${ }^{19}$ Sobre el tema ver "Cátedra Libre Ciencia, Política y Sociedad". (2018). Publicaciones científicas, ¿comunicación o negocio editorial? Ciencia, tecnología y política, 1(1), 005. https://doi.org/10.24215/26183188e005
} 